\title{
Field Test Research and Numerical Simulation on Aerodynamic Deloading Characteristics of V-Shaped Noise Barrier
}

\author{
Ji Zhao, Ning Zhi and Lü Ming \\ School of Mechanical, Electronic and Control Engineering, Beijing Jiaotong University, Beijing 100044, China.
}

\begin{abstract}
(Received 11 December 2017; accepted 17 October 2018)
With the rapid development of the high-speed railway in China, the problems of the noise pollution induced by passing trains emerge. Theoretically, the V-shaped noise barrier is of pretty good performance of noise-reduction and load-shedding. To assess the practical aerodynamic deloading characteristics of the V-shaped noise barrier, a full-scale field test was carried out at three measuring-sections equipped with noise barriers of different heights. In order to quantify the research work, the impact strength and deloading rate were selected as indicators. The effects of train speeds, train types and barrier heights are studied. This study includes the variations of impact strength and deloading rate in vertical directions. Meanwhile, 2D numerical simulation research is conducted to analyze the experimental results from the angle of mechanism. It is observed that the aerodynamic load acting on the surface of the V-shaped noise barrier was weaker and more uniform compared with conventional barrier. The flow field distribution influenced the deloading characteristics of the V-shaped noise barrier significantly. Moreover, the load-shedding effect of V-shaped noise barrier, when CRH380AM passed by, was slightly better than CRH380A. The deloading rate improved with the increasing of the noise barrier height in general.
\end{abstract}

\section{INTRODUCTION}

The mileage of the high-speed railway in China has been ranked first around the world since the end of 2013. Meanwhile, with the train speed increasing gradually, the noise pollution induced by passing trains significantly affects the life and fitness of the residents along the line. ${ }^{1}$

Equipping railway lines with noise barriers is an effective way to alleviate noise pollution. Properly raising the height of noise barriers leads to a better noise reduction effect. ${ }^{2}$ However, inherent limitation of conventional noise barrier makes it hard to promote the noise reduction effect in the manner mentioned above. This hampers its further popularization and application in the domain of high-speed railway for the sake of railway traffic safety. When a high-speed train passes through the section equipped with noise barriers, intense aerodynamic load induced by the passing train acts on the surface of noise barrier which results in alternating and transient push and suck impact to the noise barrier. With the train speed increasing, the aerodynamic load may exceed the load-bearing capacity of the steel pillar and unit plate of the noise barrier resulting in structural damage and even severe accidents. ${ }^{3}$ As opposed the conventional noise barrier, the V-shaped noise barrier is of good comprehensive performance of noise-reduction and loadshedding, a broad application prospect is expected.

As far as the deloading characteristics of the V-shaped barrier are concerned, some research has been carried out through numerical simulations and wind tunnel experiments. Liu W equated the V-shaped noise barrier and porous media to study its deloading characteristics. ${ }^{4}$ Three-dimensional models, including high-speed trains, were built up by Liu J to make a comparative investigation about the structure stress of conventional and V-shaped noise barriers. ${ }^{5}$ Additionally, a wind tunnel test on several specimens of noise barrier was carried out by $\mathrm{Li}$ Feng to screen out the noise barrier with better performance preliminarily. ${ }^{6}$ Though there is no information available about field test researches aimed at V-shaped noise barriers, some full scale and scale experiments have been conducted to investigate the aerodynamic effects on trackside and roadside structures due to the passing vehicles and wind load. A full-scale test was carried out by Quinna A.D to investigate the forces acting on flat plates induced by wind and vehicles. ${ }^{7,8}$ Carassale $\mathrm{L}$ and Brunenghi $\mathrm{M}$ conducted an experimental campaign on a steel frame located close to a railway to study its dynamic response to the aerodynamic effects produced by passing trains. ${ }^{9}$ Additionally, Cali P M and Lichtneger P also carried out experimental research focusing on the effects of vehicle-induced gusts on highway sign structures and roadside plates. ${ }^{10,11}$

The field test was indispensable to investigate the deloading characteristics objectively, while the numerical simulation research made it possible to study the microscopic flow field distribution. In this paper, the results of both the field test and the numerical simulation were presented. Impact strength and pressure deloading rate were picked out as indicators for assessing load-shedding effect, and the contours of velocity and pressure were displayed for mechanism study. The researched works contributed to delivering a broad database for a proper assessment of the deloading characteristics and structure optimization of the V-shaped noise barrier.

\section{NUMERICAL SIMULATION RESEARCH}

A two-dimensional numerical simulation research was conducted. Though the aerodynamic load acted on the noise barrier steadily and the models were simplified to some extent, which resulted in differences with actual situations, the microscopic flow field distribution contributed to the mechanism study of the deloading characteristics of the V-shaped noise barrier and provided a necessary supplement to the field test research. 


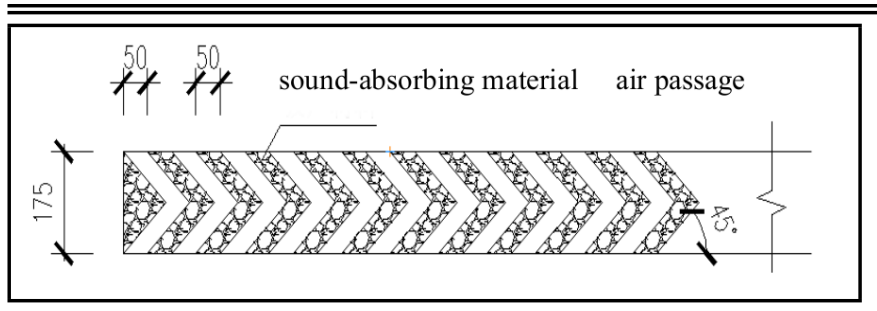

Figure 1. Geometric model of the V-shaped noise barrier.

\subsection{Physical Model and Mesh Generation}

The geometric model of the $\mathrm{V}$-shaped noise barrier is shown in Fig. 1. Because of the negligible gap between the plates of the convention noise barrier, it was simplified to solid plate with the same geometric size.

With the help of Gambit, the mesh generation was finished. The control domain was 4 meters high and 1 meter wide. The size of the mesh was reduced to $3 \mathrm{~mm}$ for refinement near the surface of the noise barrier and inside the air passage corresponding to the meshes of $10 \mathrm{~mm}$ away from the positions mentioned above. The total amount of mesh for the conventional and V-shaped noise barrier was 200000 and 450000 approximately.

\subsection{Definite Conditions}

The numerical simulation was finished with the help of CFD software of FLUENT. The inlet boundary condition was set as velocity-inlet, and the up and down sides, as well as the outlet boundary conditions of the computational domain were set as pressure-outlet. The Simple algorithm and the turbulence model of $k-\varepsilon$ in the form of RNG were adopted for numerical simulation research.

\section{DESCRIPTION OF THE EXPERIMENT}

\subsection{Basic Information of the Measuring Sections}

The field test was based on the $\mathrm{Da} \mathrm{Xi}$ passenger special line and was carried out at three measuring-sections, namely the bridge section, the east section on embankment and the west section on embankment. The height of the noise barriers were $2.15 \mathrm{~m}, 2.95 \mathrm{~m}$, and $3.95 \mathrm{~m}$ respectively. Moreover, the distances between the noise barrier and the track at the bridge section, the east section on embankment and the west section on embankment are $2650 \mathrm{~mm}, 4860 \mathrm{~mm}$ and $4860 \mathrm{~mm}$.

As displayed in Fig. 2, the macroscopic profiles of the noise barriers at the three sections are generally identical, but acrylic plates were mounted at the top of the noise barriers of the west line on embankment.

The unit plate of the $\mathrm{V}$-shaped noise barrier is shown in Fig. 3a. There is an air passage between the plates of the V-shaped noise barrier, which makes it possible for the compressed air to escape to the exterior space. The unit plate of the so-called conventional noise barrier is shown in Fig. 3b. The gap between the unit plates is negligible, and the aerodynamic load induced by passing trains acts on the noise barrier wholly.

\subsection{Two Kinds of Testing Train Models}

Two kinds of high-speed trains were mentioned in this field test, namely CRH380A-type EMU and CRH380AM-type EMU, just as shown in Fig. 4.

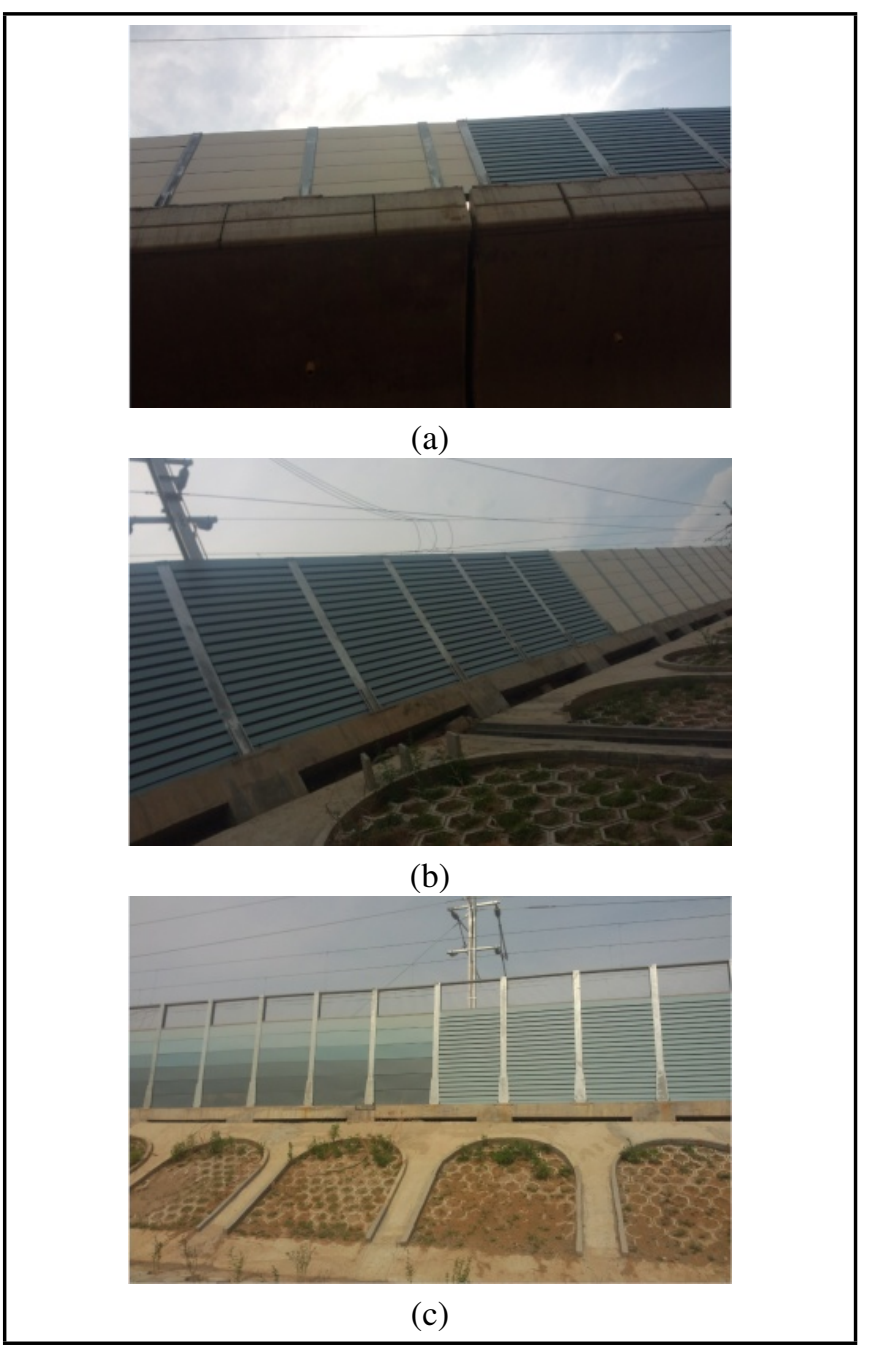

Figure 2. Three measuring-sections, (a) bridge section (b) east section on embankment (c) west section on embankment.

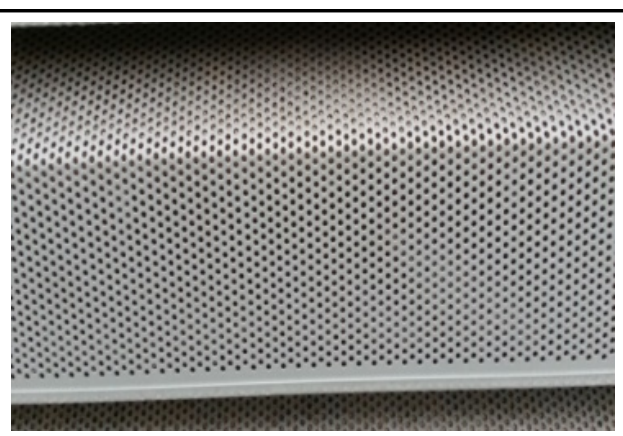

(a)

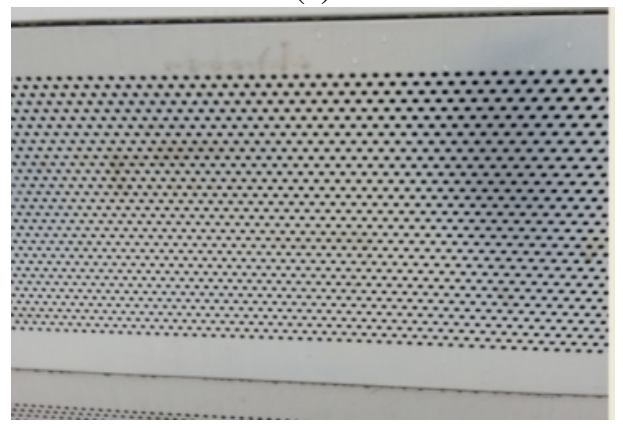

(b)

Figure 3. Unit plates of two kinds of noise barriers, (a) unit plate of V-shaped noise barrier, (b) unit plate of conventional noise barrier. 


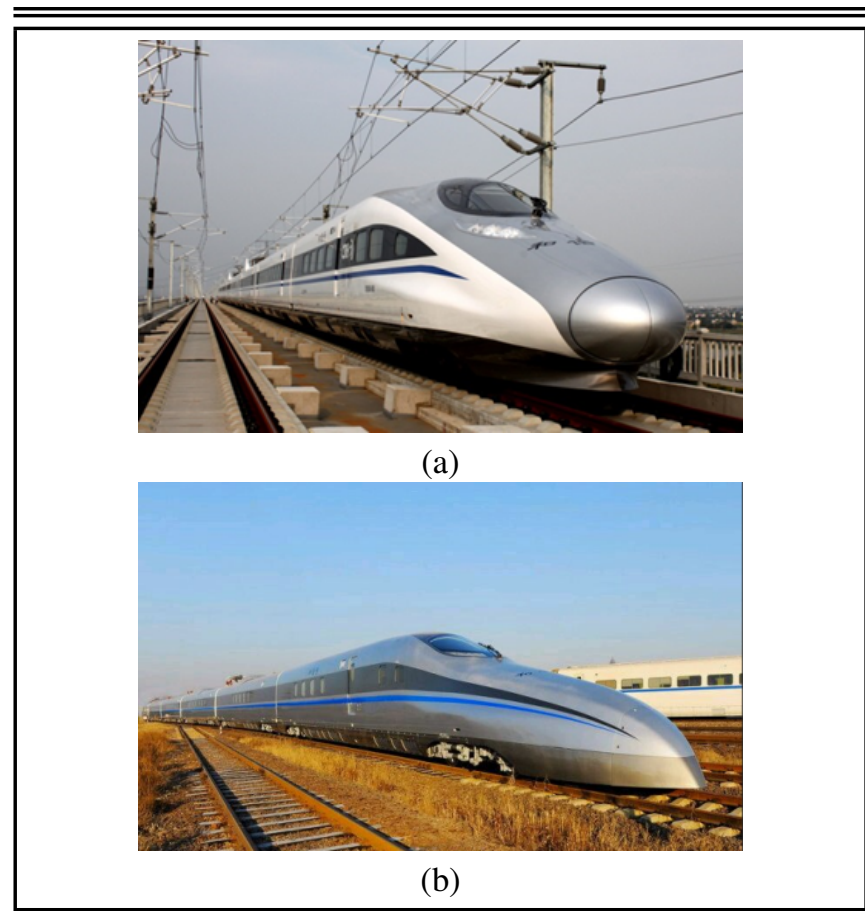

Figure 4. Two kinds of testing train models (a) CRH380A-type EMU, (b) CRH380AM-type EMU.

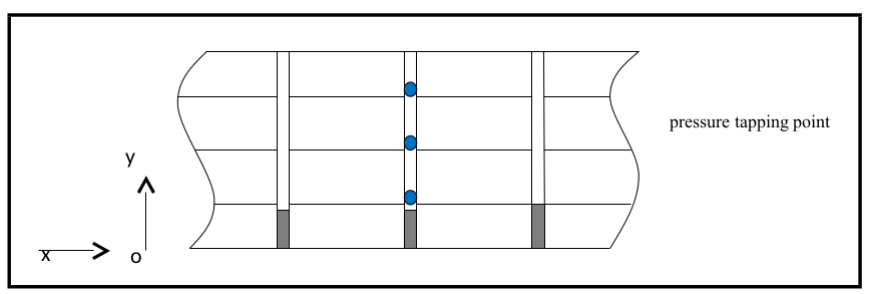

Figure 5. Layout scheme of pressure tapping points.

The difference of outlines of the fronts can be easily discovered. The front of CRH380A-type EMU was relatively flat; while the streamlined profile of the CRH380AM-type EMU was obvious. The difference triggered changes of air flow field and then the aerodynamic load acting on the surface of noise barrier.

\subsection{Layout Scheme of Pressure Tapping Points}

The layout scheme of pressure tapping points on the surfaces of noise barriers is sketched in Fig. 5. Pressure transducers were stuck on the H-shaped steel pillar in the y direction to investigate the aerodynamic deloading characteristics at different regions. The plane on which the pressure transducers were mounted was parallel with the $x$ direction in which the trains passed by.

The heights of noise barriers at different measuring-sections were different, so the practical orientation of the pressure transducers varied correspondingly, but the proportions between their installation heights and the total heights of the noise barriers were identical, namely $1 / 4,1 / 2$ and $3 / 4$.

\subsection{Establishment and Calibration of the Test System}

The testing system was consisted of 18 pressure transducers, 6 data collectors, 6 personal computers, 2 power supplies and

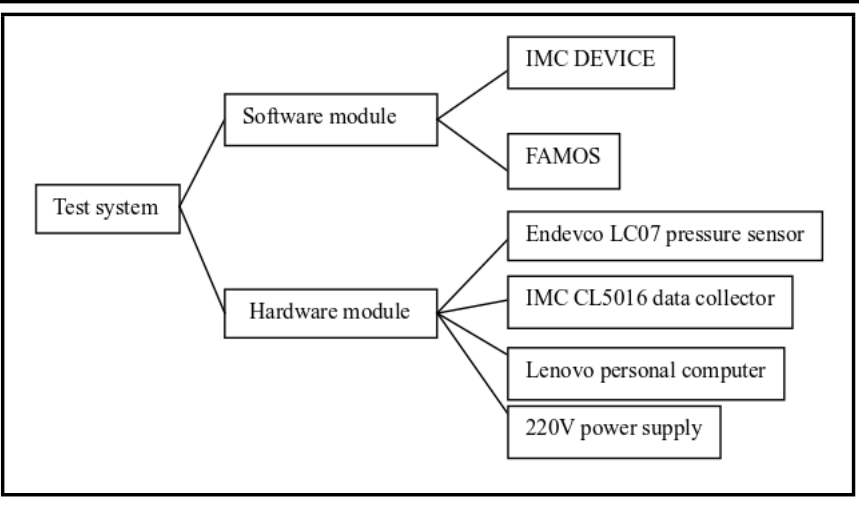

Figure 6. Block diagram of the test system.

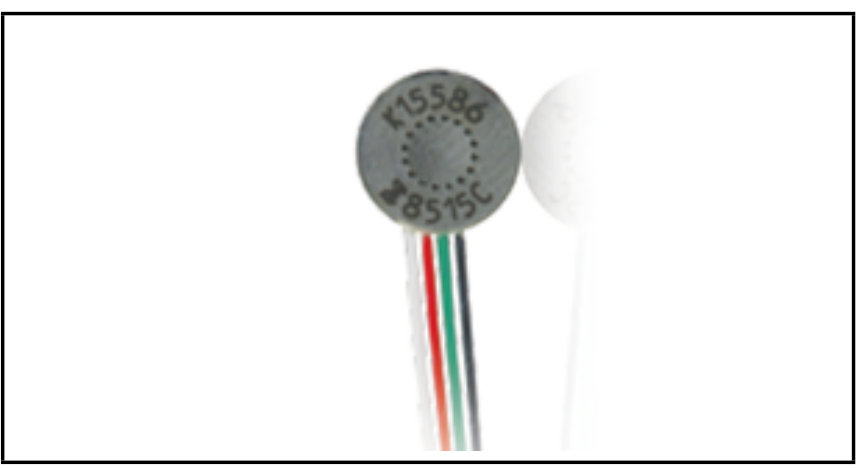

Figure 7. Endevo $8515 \mathrm{C}$ pressure transducer.

relative software for parameter setting, real-time monitoring and data processing, just as shown in Fig. 6.

Fig. 6 gives the block diagram of the test system. The outputs from these pressure transducers were amplified and transformed into a PC. The signal was filtered by the Butterworth low-pass filter at $100 \mathrm{~Hz}$ to avoid signal aliasing preliminarily. The sampling frequency was set at $500 \mathrm{~Hz}$.

The key part of the test system was the Endevo $8515 \mathrm{C}$ pressure transducer, as is shown in Fig. 7.

The Endevo 8515C pressure transducer was based on the piezoresistive effect of semiconductor material, and was considered to be one of the best pressure transducers for faster high-frequency response. Moreover, the properties of small size, light weight, wide working temperature range, and durableness made the Endevo $8515 \mathrm{C}$ pressure transducer meet the requirements of the field test.

The test system is calibrated based on the conclusion that the peak of fluctuating pressure on surface of the noise barrier is proportional to the square of train speed. ${ }^{12}$ The fitting curve is drawn according to the measured pressures at the bridge section, just as shown in Fig. 8.

The square of the correlation coefficient of the measured pressures and the fitting curve $\mathrm{P}=0.00454 \mathrm{v} 2$ was 0.97796 , the maximum relative error between the measured pressure and fitted value was $4.60 \%$, which was less than $5 \%$. We arrived at the conclusion that the measured peak of fluctuating pressure was proportional to the square of train speed indeed.

\section{RESULTS AND DISCUSSIONS}

The train speeds mentioned in this paper are no less than $260 \mathrm{~km} / \mathrm{h}$, as a result, the action time of aerodynamic load is extremely short, so the effects of meteorological condition and 


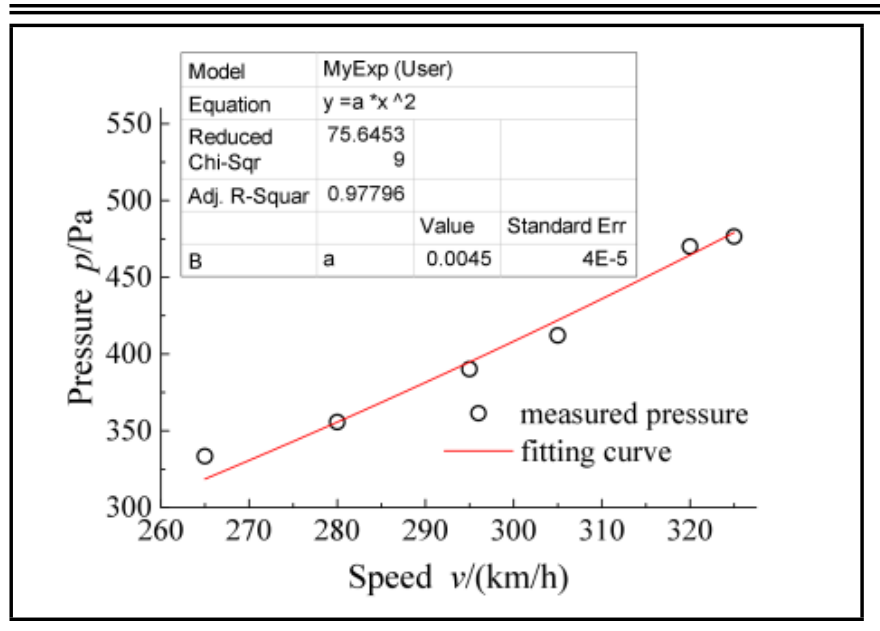

Figure 8. Comparison between the measured pressure values and the fitting curve.

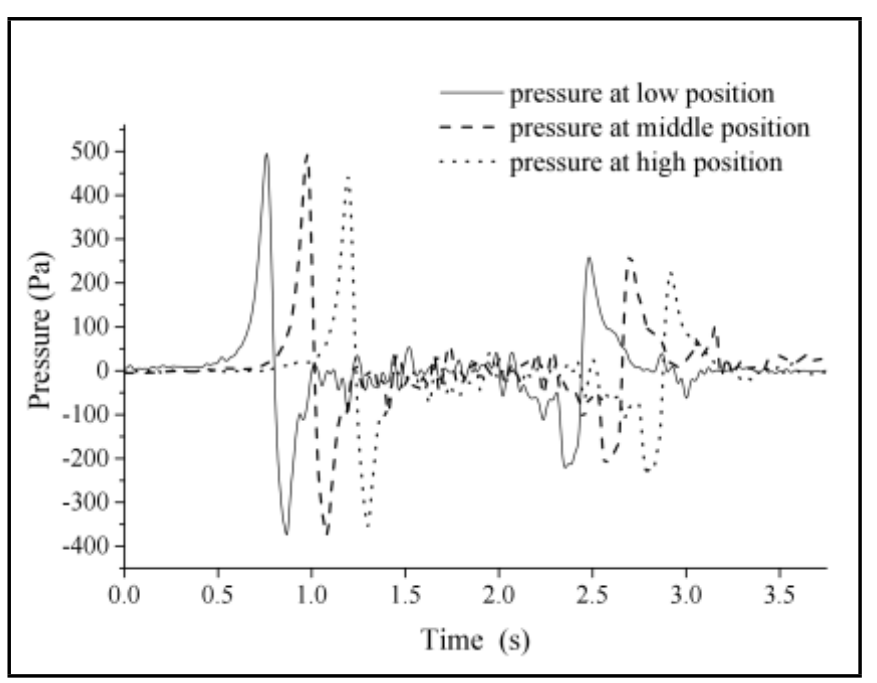

Figure 9. Time-history curves of pressure at different positions when CRH380AM passed the conventional noise barrier at the bridge section with the speed of $340 \mathrm{~km} / \mathrm{h}$.

the wind load are ignored in this paper. The load induced by passing trains acts on the surface of noise barriers laterally, so the measured pressure can be considered as static pressure approximately.

Just as shown in Fig. 9, the pulsating pressure shows a head wave, a coda wave and the magnitude of the head wave is greater than that of the coda wave significantly. The pressure in high position is less than the pressures in the middle and low position while the latter two are very close, which is consistent with the numerical simulation result. ${ }^{6}$ Given the facts mentioned above, research work mainly focuses on the head wave in the low position in this paper.

\subsection{Deloading Characteristics From the Impact Strength Perspective}

The pressure induced by the passing train generates fierce impact to the noise barrier. The deloading characteristics can be assessed by the impact strength. The impact strength $Q$ is calculated as a function of pressure difference $\Delta p$ and time difference $\Delta t$ :

$$
Q=\left|\frac{\Delta p}{\Delta t}\right| .
$$

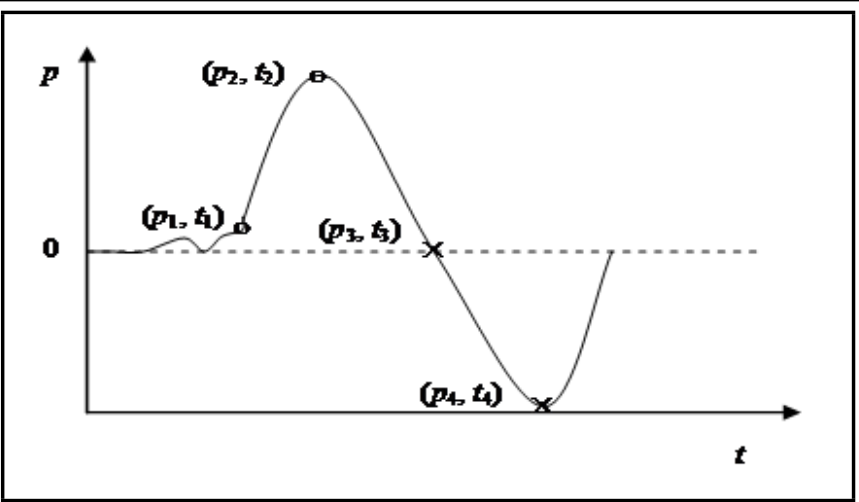

Figure 10. Sketch of the definition on $Q$.

It should be noted that the pressure began increasing slowly before the train had reached the noise barrier. This is due to the compressibility and spread of the air. To avoid the effect of this phenomenon, different principles were adopted for choosing the start point when calculating the peak and trough impact strength. The value, namely $10 \%$ of the peak, $p_{1}$, was chosen as the start point when calculating the peak impact strength $Q_{p}=\left(p_{2}-p_{1}\right) /\left(t_{2}-t_{1}\right)$, while the base value (null point), $p_{3}$, was chosen as the start point when calculating the trough impact strength $Q_{p}=\left(p_{3}-p_{4}\right) /\left(t_{3}-t_{4}\right)$. A sketch is made to describe the definition as shown in Fig. 10.

The peak and trough impact strength induced by CRH380A and CRH380AM passing the west line on embankment at typical speed stages are taken as examples because of the complete speed range, and the basic information is illustrated by Fig. 11, Table 1 and Table 2 .

The impact strength rises as the train speed increases. The peak and trough impact strength acting on the V-shaped noise barrier are weaker than that acting on the conventional noise barrier at all the speed stages. To investigate the load-shedding effect of the V-shaped noise barrier quantitatively, the maximum values of peak and trough impact strength at the three measuring-sections are listed in Table 3.

In most cases, the maximum values of the impact strength on the V-shaped noise barrier are smaller as opposed to the conventional noise barrier. As opposed to the conventional noise barrier, the trough impact strength of the V-shaped noise barrier reduces $28.95 \%$ at least and $53.63 \%$ at most corresponding to $9.44 \%$ and $27.21 \%$ of the peak impact strength. The reduction degree of the trough impact strength is more significant as opposed to the peak impact strength. What's more, the trough impact strength can be more than 3 times stronger than the peak impact strength, so the effect of trough impact should not be ignored.

The weakening effect on the impact strength is due to the change of flow field distribution around and inside the noise barrier. The side view of velocity field distribution of the air under the wind speed of $20 \mathrm{~m} / \mathrm{s}$ is shown in Fig. 12, and the wind blows from the left side.

The velocity difference between the front and back of the conventional noise barrier is greater than that of the V-shaped noise barrier. The air behind the conventional noise barrier is almost static, by contrast, the air confronting the V-shaped noise barrier escapes through the passage to outer space continuously. The velocity difference of the air in the passage should not be ignored. The acceleration of the air surmounting the sharp corner promotes its escape further and thus alleviates the 
Table 1. Impact strength at bottom when CRH380A passed the right line on the subgrade (C-type: conventional noise barrier, V-type: V-shaped noise barrier).

\begin{tabular}{||c|c|c|c|c|c|c|c||}
\hline Speed $(\mathrm{km} / \mathrm{h})$ & Type & $\Delta p$-peak $(\mathrm{Pa})$ & $\Delta t$-peak $(\mathrm{ms})$ & $Q_{p}(\mathrm{kPa} / \mathrm{s})$ & $\Delta p$-trough $(\mathrm{Pa})$ & $\Delta t$-trough $(\mathrm{ms})$ & $Q_{t}(\mathrm{kPa} / \mathrm{s})$ \\
\hline \multirow{2}{*}{290} & C-type & 247.91 & 201.81 & 1.23 & 255.39 & 55.04 & 4.64 \\
& V-type & 185.72 & 175.30 & 1.06 & 145.91 & 94.05 & 1.55 \\
& C-type & 290.57 & 184.25 & 1.58 & 306.53 & 63.50 & 4.83 \\
& V-type & 221.13 & 173.69 & 1.27 & 161.66 & 76.87 & 2.10 \\
& C-type & 337.42 & 213.68 & 1.58 & 306.55 & 61.13 & 5.01 \\
& V-type & 234.73 & 182.44 & 1.29 & 158.43 & 70.23 & 2.26 \\
330 & C-type & 356.36 & 214.29 & 1.66 & 327.99 & 62.68 & 5.23 \\
& V-type & 266.18 & 198.21 & 1.34 & 179.73 & 67.29 & 2.67 \\
340 & C-type & 371.03 & 199.25 & 1.86 & 353.61 & 61.44 & 5.76 \\
& V-type & 284.04 & 196.86 & 1.44 & 173.75 & 65.98 & 2.63 \\
355 & C-type & 435.43 & 186.13 & 2.34 & 383.69 & 51.84 & 7.40 \\
& V-type & 296.41 & 141.89 & 2.09 & 218.30 & 62.77 & 3.48 \\
& C-type & 440.21 & 181.92 & 2.42 & 429.68 & 50.75 & 8.47 \\
& V-type & 305.60 & 139.25 & 2.19 & 226.25 & 59.05 & 3.83 \\
& C-type & 486.35 & 169.33 & 2.87 & 457.98 & 49.58 & 9.24 \\
& V-type & 346.02 & 142.75 & 2.42 & 234.90 & 56.28 & 4.17 \\
& C-type & 513.15 & 154.49 & 3.32 & 485.93 & 49.72 & 9.77 \\
& V-type & 350.71 & 135.50 & 2.59 & 255.92 & 56.49 & 4.53 \\
\hline
\end{tabular}

Table 2. Impact strength at bottom when CRH380AM passed the right line on the subgrade (C-type: conventional noise barrier, V-type: V-shaped noise barrier).

\begin{tabular}{||c|c|c|c|c|c|c|c|}
\hline Speed $(\mathrm{km} / \mathrm{h})$ & Type & $\Delta p$-peak $(\mathrm{Pa})$ & $\Delta t$-peak $(\mathrm{ms})$ & $Q_{p}(\mathrm{kPa} / \mathrm{s})$ & $\Delta p$-trough $(\mathrm{Pa})$ & $\Delta t$-trough $(\mathrm{ms})$ & $Q_{t}(\mathrm{kPa} / \mathrm{s})$ \\
\hline \multirow{2}{*}{285} & C-type & 212.96 & 212.14 & 0.99 & 178.48 & 77.31 & 2.31 \\
& V-type & 146.71 & 243.22 & 0.60 & 89.19 & 73.26 & 1.22 \\
& C-type & 218.07 & 212.65 & 1.03 & 198.00 & 78.54 & 2.52 \\
& V-type & 150.50 & 237.89 & 0.63 & 95.42 & 67.11 & 1.42 \\
& C-type & 249.76 & 210.93 & 1.18 & 215.65 & 76.48 & 2.82 \\
& V-type & 173.02 & 234.43 & 0.74 & 108.35 & 64.74 & 1.67 \\
325 & C-type & 262.15 & 202.94 & 1.29 & 243.66 & 72.70 & 3.35 \\
& V-type & 182.01 & 231.55 & 0.79 & 117.13 & 65.98 & 1.78 \\
335 & C-type & 293.92 & 201.45 & 1.46 & 257.48 & 65.59 & 3.93 \\
& V-type & 206.73 & 205.37 & 1.01 & 129.06 & 66.35 & 1.95 \\
345 & C-type & 317.94 & 168.03 & 1.89 & 285.43 & 57.52 & 4.96 \\
& V-type & 222.48 & 173.62 & 1.28 & 138.47 & 60.53 & 2.29 \\
355 & C-type & 356.04 & 169.78 & 2.10 & 347.02 & 59.03 & 5.88 \\
& V-type & 239.67 & 149.29 & 1.61 & 180.91 & 65.51 & 2.76 \\
365 & C-type & 390.92 & 159.83 & 2.45 & 340.29 & 56.87 & 5.98 \\
& V-type & 251.69 & 132.96 & 1.89 & 177.96 & 56.09 & 3.17 \\
& C-type & 400.59 & 141.72 & 2.83 & 369.52 & 54.62 & 6.77 \\
& V-type & 267.53 & 130.14 & 2.06 & 178.19 & 55.18 & 3.23 \\
\hline
\end{tabular}

Table 3. Maximum values of peak and trough impact strength (kPa/s) (C-type: conventional noise barrier, V-type: V-shaped noise barrier).

\begin{tabular}{|c|c|c|c|c|c|c|c|c||}
\hline \multirow{3}{*}{ Measuring section } & \multicolumn{3}{|c|}{ CRH380A } & \multicolumn{3}{c||}{ CRH380AM } \\
\cline { 2 - 10 } & \multicolumn{2}{|c|}{$Q_{p}$} & \multicolumn{2}{c|}{$Q_{t}$} & \multicolumn{2}{c|}{$Q_{p}$} & \multicolumn{2}{c|}{$Q_{t}$} \\
\cline { 2 - 10 } & C-type & V-type & C-type & V-type & C-type & V-type & C-type & V-type \\
\hline Bridge section & 2.82 & 3.44 & 7.75 & 4.12 & 3.60 & 3.26 & 5.32 & 3.78 \\
East line on embankment & 2.01 & 1.61 & 6.74 & 4.36 & 1.53 & 1.15 & 4.40 & 2.99 \\
West line on embankment & 3.32 & 2.59 & 9.77 & 4.53 & 2.83 & 2.06 & 6.77 & 3.23 \\
\hline
\end{tabular}




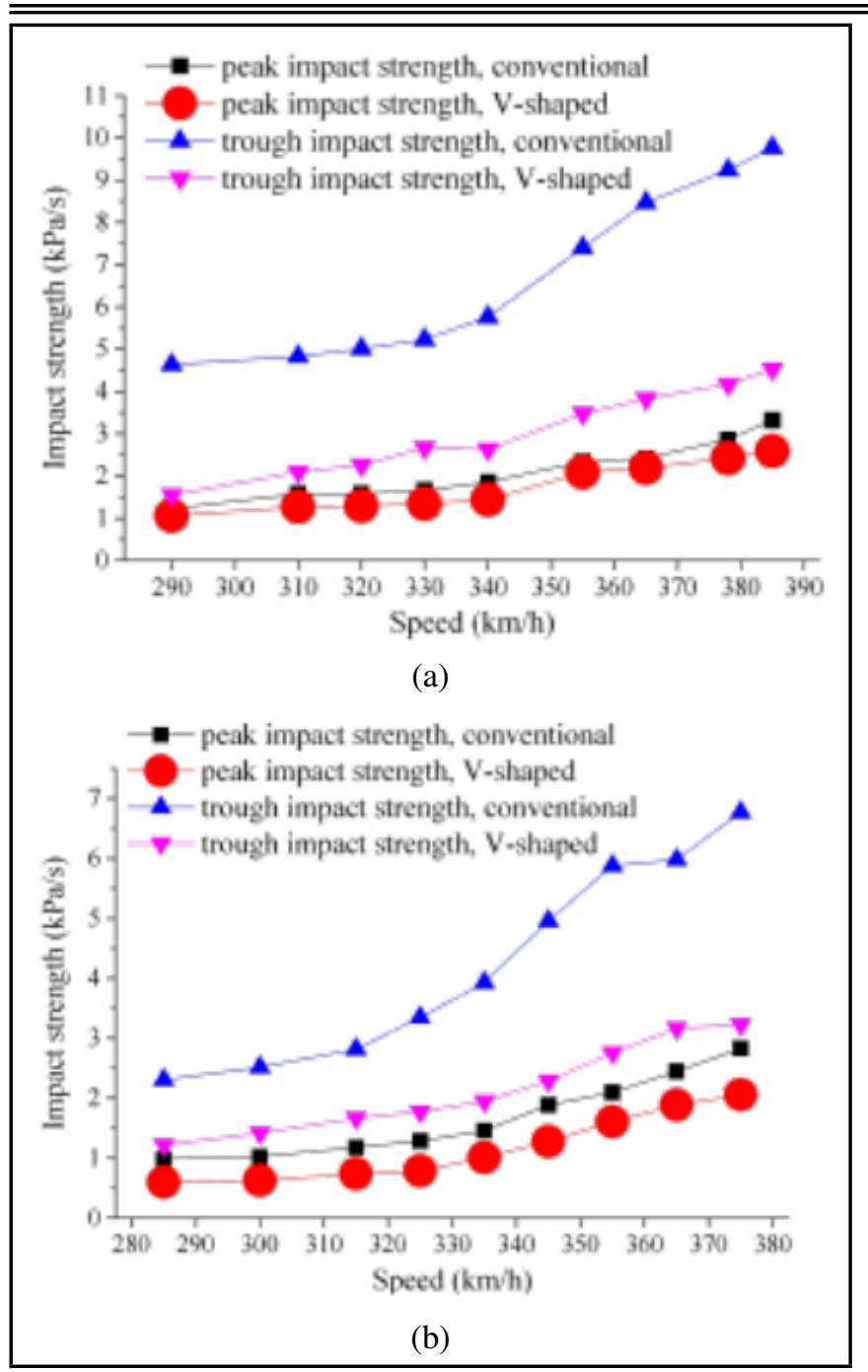

Figure 11. Peak and trough impact strength-speed curves of conventional and V-shaped noise barriers at the west line on embankment, (a) CRH380A, (b) CRH380AM.

degrees of the air being squeezed and the noise barrier being impacted, which results in weaker impact strength on the surface of the V-shaped noise barrier.

The stronger trough impact and the better load-shedding effect on it jointly result in the smaller difference between the peak and trough impact strength. The average differences between the peak and trough impact strength at typical speed stages are shown in Fig. 13.

It can be seen in the Fig. 11 that the difference between peak and trough impact strength becomes greater with the train speed increasing, especially for the conventional noise barrier. Fig. 13 illustrates that as opposed to the conventional noise barrier, the $\mathrm{V}$-shaped noise barrier minifies the difference between the peak and trough impact strength and balances the aerodynamic load during the processes of pressure mounting to the peak and sliding to the trough, which reduces the probability of structure instability of the noise barrier.

The average impact strength (the arithmetic mean of the peak and trough impact strength) of the west line on embankment is listed in Table 4 to study the effect of train shape.

Under the premise that the speeds of CRH380AM are higher than that of $\mathrm{CRH} 380 \mathrm{~A}$ by $5 \mathrm{~km} / \mathrm{h}$ or $10 \mathrm{~km} / \mathrm{h}$, the average impact strength induced by CRH380AM is apparently weaker than that induced by CRH380A regardless of the type of noise

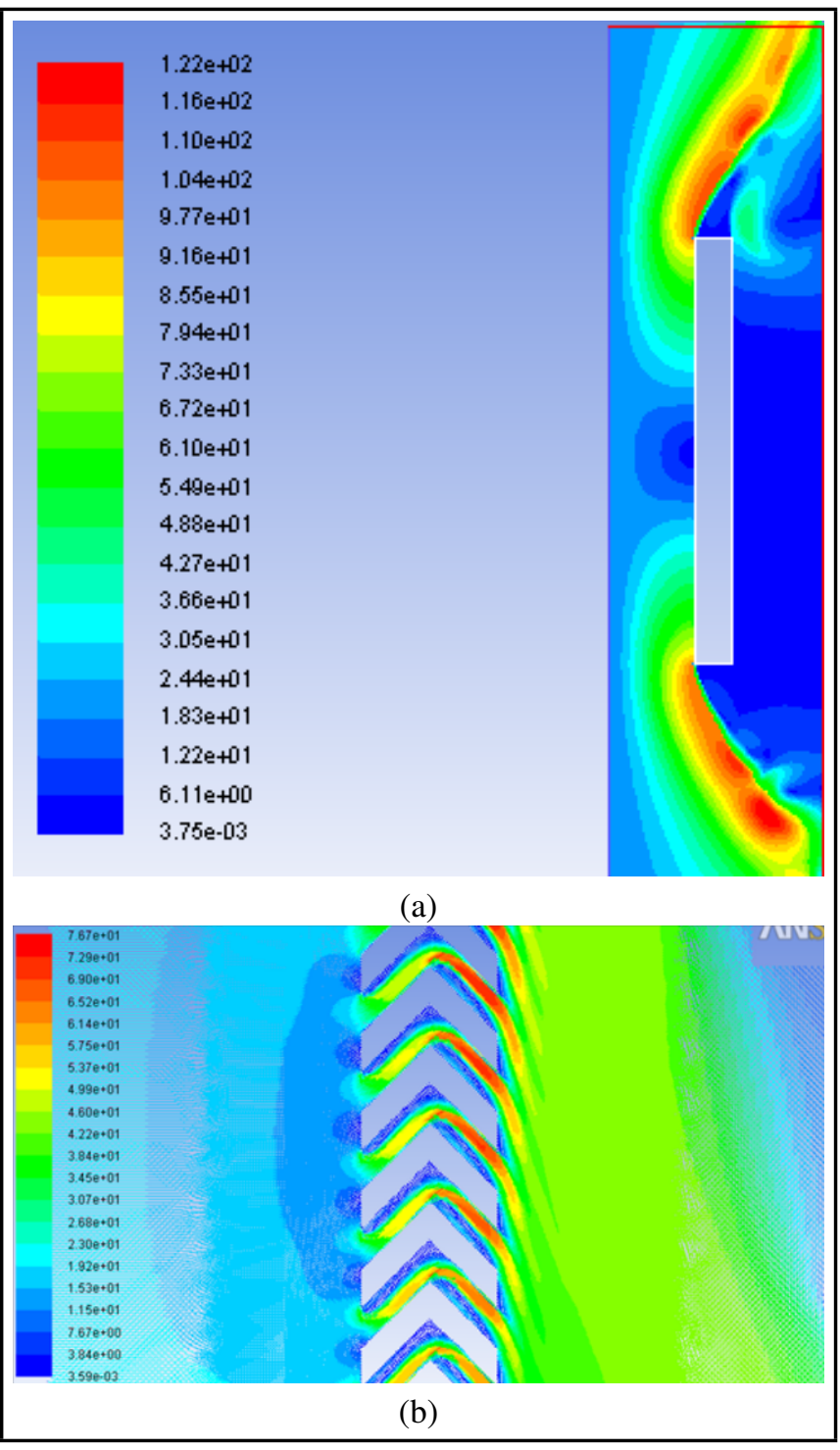

Figure 12. Side view of velocity field distribution around and inside the (a) conventional noise barrier and (b) $\mathrm{V}$-shaped noise barrier at the wind speed of $20 \mathrm{~m} / \mathrm{s}$.

Table 4. Average impact strength induced by CRH380A and CRH380AM at the west line on embankment (Note: in the cell of speed, the two values represent the speed of CRH380A and CRH380AM respectively).

\begin{tabular}{||c|c|c|c|c||}
\hline \multirow{2}{*}{ Speed $(\mathrm{km} / \mathrm{h})$} & \multicolumn{4}{|c|}{ Average impact strength (kPa/s) } \\
\cline { 2 - 5 } & Conventional noise barrier & V-shaped noise barrier \\
\cline { 2 - 5 } & CRH380A & CRH380AM & CRH380A & CRH380AM \\
\hline $290 / 300$ & 2.94 & 1.78 & 1.31 & 1.03 \\
$310 / 315$ & 3.21 & 2.00 & 1.69 & 1.21 \\
$320 / 325$ & 3.30 & 2.32 & 1.78 & 1.29 \\
$330 / 335$ & 3.45 & 2.70 & 2.01 & 1.48 \\
$340 / 345$ & 3.81 & 3.43 & 2.04 & 1.79 \\
$355 / 365$ & 4.87 & 4.22 & 2.79 & 2.53 \\
$365 / 375$ & 5.45 & 4.80 & 3.01 & 2.65 \\
\hline
\end{tabular}

barrier. As for the conventional noise barrier, the maximum average impact strength induced by CRH380AM is $4.80 \mathrm{kPa} / \mathrm{s}$ at the speed of $375 \mathrm{~km} / \mathrm{h}$, which is approximately equal to the $4.87 \mathrm{kPa} / \mathrm{s}$ induced by CRH380A at the speed of $355 \mathrm{~km} / \mathrm{h}$ When it comes to the $\mathrm{V}$-shaped noise barrier the situation is aggravated, the difference between $2.65 \mathrm{kPa} / \mathrm{s}$ and $2.79 \mathrm{kPa} / \mathrm{s}$ reaches $0.14 \mathrm{kPa} / \mathrm{s}$. Based on the results mentioned above, the CRH380AM-type EMU is beneficial to the structural stability of noise barrier to some extent. 


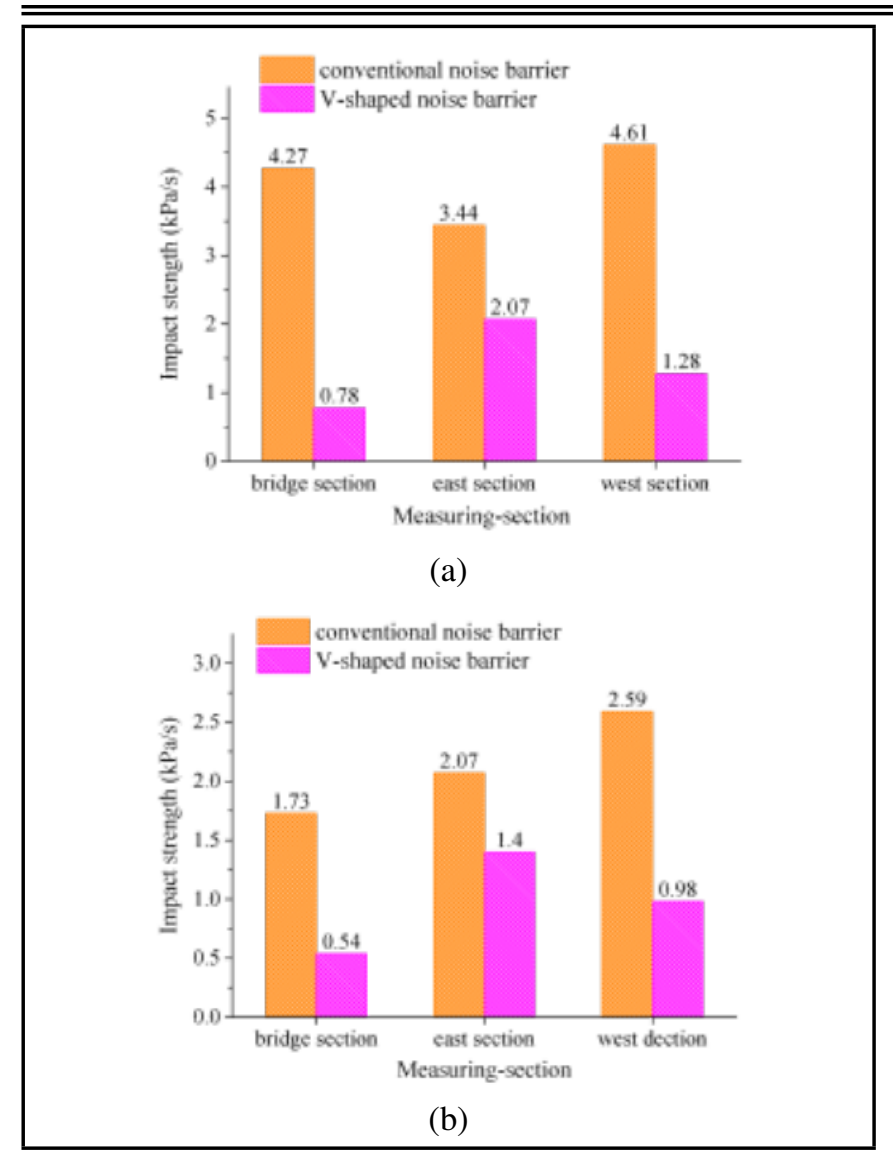

Figure 13. Average difference between peak and trough impact strength at typical speeds induced by (a) CRH380A-type EMU and (b) CRH380AM-type EMU.

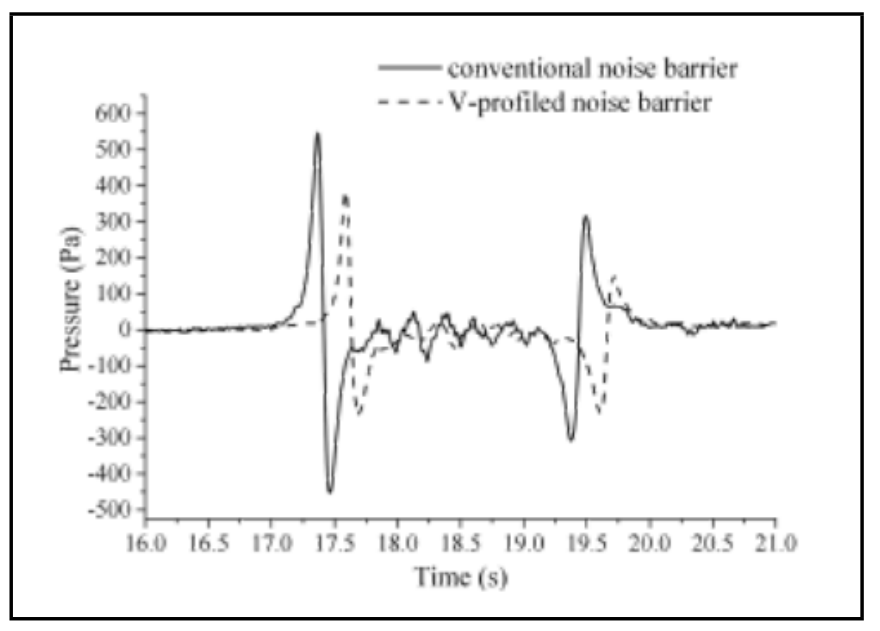

Figure 14. Time-history curves of pulsating pressure acting on conventional and V-shaped noise barrier.

\subsection{Deloading Characteristics From the Deloading Rate Perspective}

The pressure deloading rate is the most pertinent indicator for investigating the aerodynamic deloading characteristics of V-shaped noise barrier. Time-history curves of the pulsating pressure acting on conventional and $\mathrm{V}$-shaped noise barrier are shown in Fig. 14.

The pulsating pressure acting on the V-shaped noise barrier represented by the dot line is significantly lower than that acting on the conventional noise barrier represented by the solid line. Special attention should be paid to the different load-

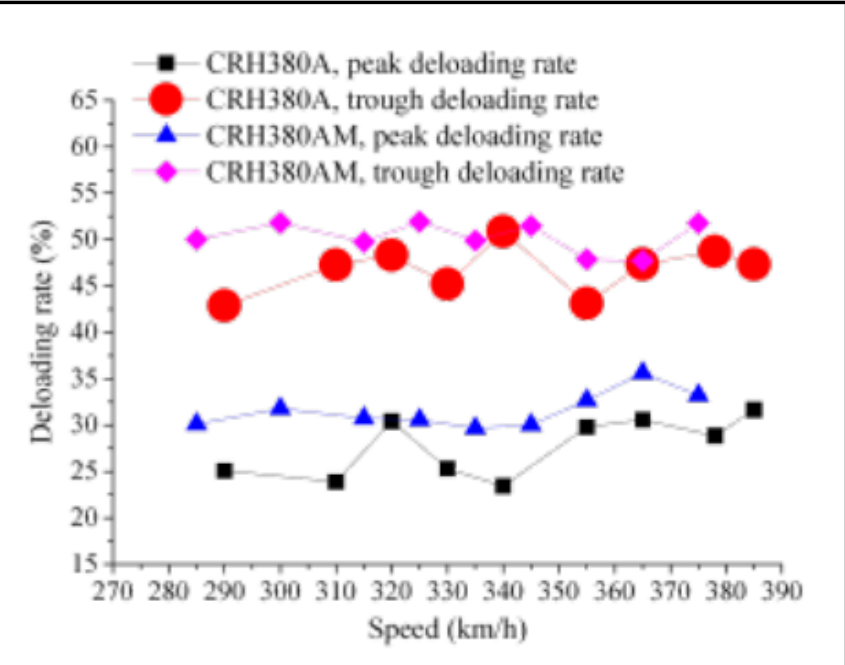

Figure 15. Peak and trough deloading rate-speed curves at the west line on embankment.

Table 5. Maximum and minimum values of deloading rate of different sections induced by CRH380A.

\begin{tabular}{|c|c|c|c|c|}
\hline \multirow{2}{*}{ Measuring section } & \multicolumn{2}{|c|}{$\begin{array}{c}\text { Peak deloading } \\
\text { rate }(\%)\end{array}$} & \multicolumn{2}{c|}{$\begin{array}{c}\text { Trough deloading } \\
\text { rate }(\%)\end{array}$} \\
\cline { 2 - 5 } & Min & Max & Min & Max \\
\hline Bridge section & 1.59 & 5.98 & 24.84 & 36.12 \\
East line on embankment & 7.58 & 18.80 & 25.27 & 32.38 \\
West line on embankment & 23.44 & 31.66 & 42.87 & 50.86 \\
\hline
\end{tabular}

shedding between the peak and trough. As for the head wave, the load-shedding effect of the trough is greater than that of the peak, while the condition of the coda wave is just the opposite.

To study this issue quantitatively, three kinds of deloading rates, the peak deloading rate $\theta_{p}$, the trough deloading rate $\theta_{t}$ and the peak-trough deloading rate $\theta_{p-t}$ of the head wave are defined. The peak, trough, and peak-trough deloading rates can be calculated as functions of pressure peaks on the surfaces of the conventional and V-shaped noise barrier, namely $p_{p(C)}$ and $p_{p(V)}$, and pressure troughs represented by $p_{t(C)}$ and $p_{t(V)}$ corresponding to the conventional and V-shaped noise barrier:

$$
\begin{aligned}
\theta_{p} & =\left|\frac{p_{p(C)}-p_{p(V)}}{p_{p(C)}}\right| \times 100 \% . \\
\theta_{t} & =\left|\frac{p_{t(C)}-p_{t(V)}}{p_{t(C)}}\right| \times 100 \% . \\
\theta_{p-t} & =\left|\frac{\left(p_{p(C)}-p_{t(C)}\right)-\left(p_{p(V)}-p_{t(V)}\right)}{p_{p(C)}-p_{t(C)}}\right| \times 100 \% .
\end{aligned}
$$

The peak and trough deloading rate-speed curves of the west section on embankment at typical speed stages are shown in Fig. 15.

In general, the peak and trough deloading rates show volatility based on a certain value, and the trough deloading rates are greater than the peak deloading rates significantly. The maximum and minimum values of peak and trough deloading rates at typical speed stages of the three measuring-sections are listed in Table 5 and Table 6 for comparative and quantitative research.

It should be noted that the load-shedding effect during the process of pressure transforming from the base value to the trough is so significant that the minimum trough deloading rate is even greater than the maximum peak deloading rate in most 
Table 6. Maximum and minimum values of deloading rate of different sections induced by CRH380AM.

\begin{tabular}{|c|c|c|c|c|}
\hline \multirow{2}{*}{ Measuring section } & \multicolumn{2}{|c|}{$\begin{array}{c}\text { Peak deloading } \\
\text { rate }(\%)\end{array}$} & \multicolumn{2}{c|}{$\begin{array}{c}\text { Trough deloading } \\
\text { rate }(\%)\end{array}$} \\
\cline { 2 - 5 } & Min & Max & Min & Max \\
\hline Bridge section & 6.20 & 17.71 & 23.11 & 30.90 \\
East line on embankment & 15.12 & 19.18 & 18.99 & 31.31 \\
West line on embankment & 29.67 & 35.61 & 47.70 & 51.93 \\
\hline
\end{tabular}

Table 7. Average peak-trough deloading rate at three measuring sections (\%).

\begin{tabular}{||c|c|c|c|}
\hline $\begin{array}{c}\text { Train } \\
\text { shape }\end{array}$ & $\begin{array}{c}\text { Bridge } \\
\text { section }\end{array}$ & $\begin{array}{c}\text { East section on } \\
\text { embankment }\end{array}$ & $\begin{array}{c}\text { West section on } \\
\text { embankment }\end{array}$ \\
\hline CRH380A & 15.63 & 19.35 & 37.34 \\
CRH380AM & 17.56 & 20.81 & 39.71 \\
\hline
\end{tabular}

cases, which is due to the change of flow field distribution as well. The side view of pressure field distribution around and inside the noise barriers at the wind speed of $20 \mathrm{~m} / \mathrm{s}$ is shown in Fig. 16 and the wind blows from the left side.

The pressure field under steady state is similar to when the fluctuating pressure induced by passing trains reaches the maximal value. It can be seen that because of the air passage, the pressure on the surface of the V-shaped noise barrier is lower as opposed to the conventional noise barrier. Special attention should be paid to the pressure gradient in the air passage. The differential pressure between the first half part of the air passage and the surface of the V-shaped noise barrier is not so great, which prevents the squeezed air from escaping further, and that is why the load-shedding effect of peak is not significant. With the front of train leaving the noise barrier, a negative pressure zone comes into being graduallyand once the pressure on the surface of the V-shaped noise barrier is lower than that in the first half part of the air passage, the air moves reversely. Meanwhile, the negative pressure zone in the last half of the air passage promotes the air in outer space to flow inward. The timely supplement of air alleviates the suck effect on the Vshaped noise barrier significantly, which results in the higher trough deloading rate and the greater reduction degree of the trough impact strength mentioned before.

For neither the impact effect of peak nor trough can be ignored, so the peak or trough deloading rate can't represent the load-shedding performance individually. The peak-trough deloading rate involves both the effect of peak and trough and is picked out for comparative study of deloading rate among different measuring-sections, just as shown in Fig. 17. The average peak-trough deloading rates based on the data points in Fig. 17 are listed in Table 7 to study the effect of train shape further.

Though the data points distribute dispersedly to some extent, the peak-trough deloading rates fluctuate based on a certain value, so the deloading rate is insensitive to the train speed. The average deloading rates at the west line on embankment induced by CRH380A and CRH380AM are $37.34 \%$ and $39.71 \%$ which exceed that of the other two sections significantly. The better deloading effect at the west line is a result of multiple factors. On one hand, the longer distance between the noise barrier and the track on the embankment leads to more energy attenuation of the air and finally affects the deloading rate. On the other hand, as the height of noise barrier increases, less air can escape above the top edge of the noise barrier into the outer space, so the air between the train and the noise barrier is squeezed more seriously, which results in more air flees though the channel between the plate of the $\mathrm{V}$-shaped

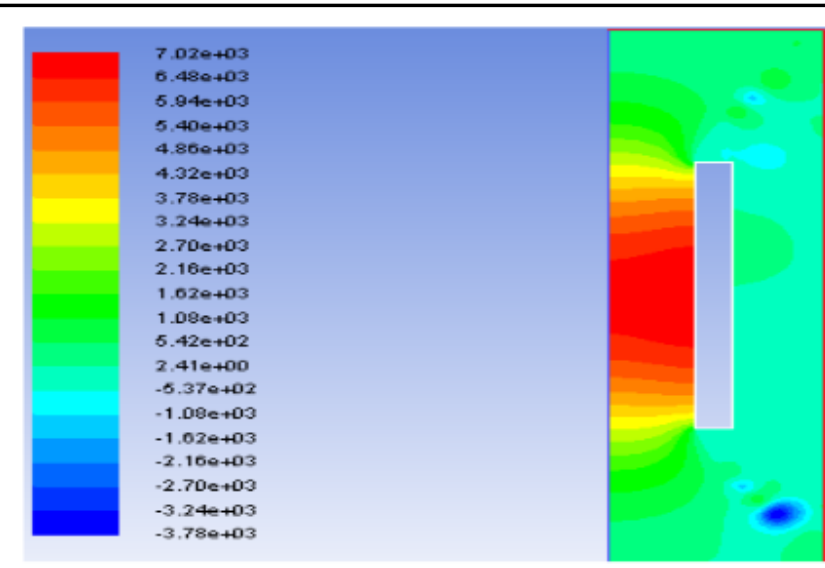

(a)

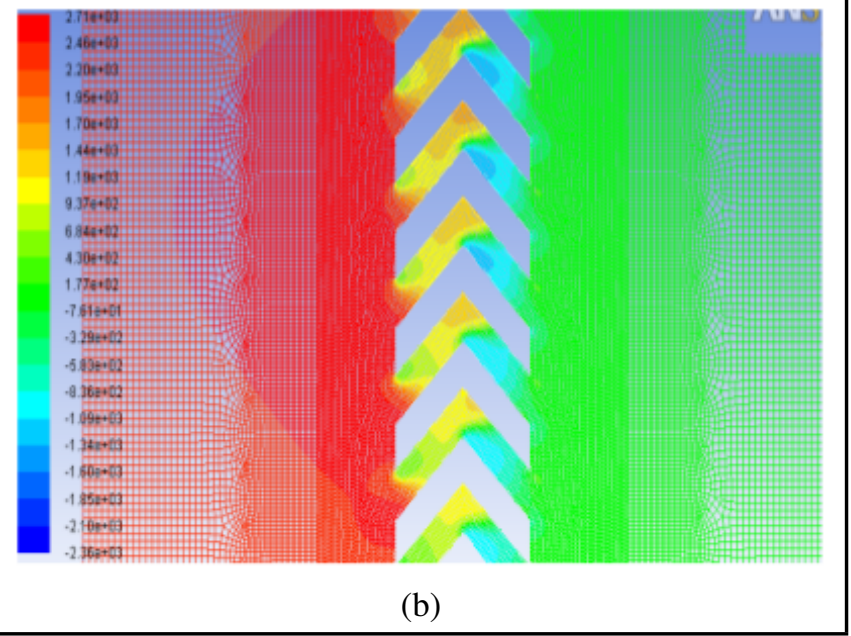

Figure 16. Side view of pressure field distribution around and inside the (a) conventional noise barrier and (b) V-shaped noise barrier at the wind speed of $20 \mathrm{~m} / \mathrm{s}$.

noise barrier. Especially for the 3.95-meter-high noise barrier, the acrylic panel mounted on the top promotes the effect of height increase significantly. The fact that the deloading rate increases with the height of noise barrier rising indicates that the $\mathrm{V}$-shaped noise barrier meets the requirement for the noise barrier applied in the domain of high-speed railway.

When it comes to the influence of train shape on the deloading rate, it should be noted trough the Table 7 that when the CRH380AM-type EMU passed by, the peak-trough deloading rate witnessed a tiny improvement by about $2 \%$, and in most cases, the interval between the peak and trough deloading rate shrank shown in Table 5 and Table 6 , which testifies that the CRH380AM-type EMU promotes the load-shedding effect and balances the deloading capability throughout the whole process of pressure pulsing.

In summary, the V-shaped noise barrier weakens the aerodynamic impact strength and demonstrates satisfactory loadshedding effect. What's more, the CRH380AM-type EMU is in favor of structural stability for the weaker impact strength, the slightly higher deloading rate, the balanced deloading capability and the uniform distribution of aerodynamic load induced by its passage. 


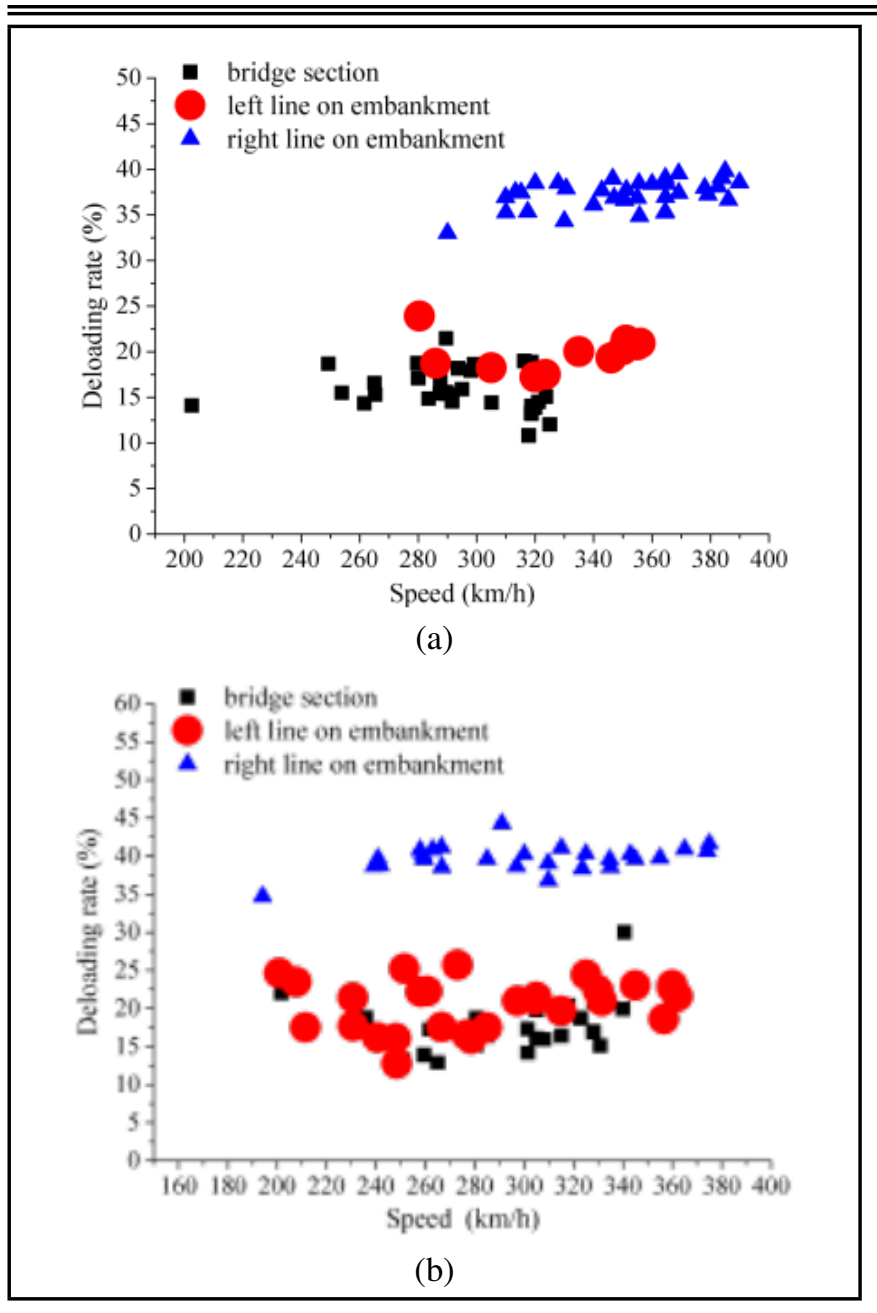

Figure 17. Comparison of peak-trough deloading rate at the three measuring sections, (a) deloading rate induced by CRH380A, (b) deloading rate induced by CRH380AM.

\subsection{Variation of Loading-Shedding Effect in Vertical Direction}

The correct evaluation of the vertical distribution of impact strength and deloading rate is relevant for several technical issues, such as fatigue enhancement and structure optimization. The cases of CRH380AM passing the bridge section and CRH380A passing the east section on embankment are taken as examples to shed light on the problem. The average impact strength-speed curves are shown in Fig. 18. The average impact strength is the arithmetic mean of peak and trough impact strength.

As opposed to the V-shaped noise barrier, the gradient of average impact strength is noticeable on the surface of conventional noise barrier when the speed of CRH380AM exceeded $305 \mathrm{~km} / \mathrm{h}$ and when CRH380A passed by within the whole speed range. The air squeezed more intensely is responsible for the stronger impact strength in the low and middle position.

The deloading rates in the vertical direction are shown in Fig. 19. Average deloading rates based on the data in Fig. 19 are listed in Table 8.

The deloading rates in the low and middle position are higher than that in the high position in general, especially in the middle position, the load-shedding effect is more significant, which is due to the gradient of impact strength in the vertical direction on the surface of conventional. In the low and

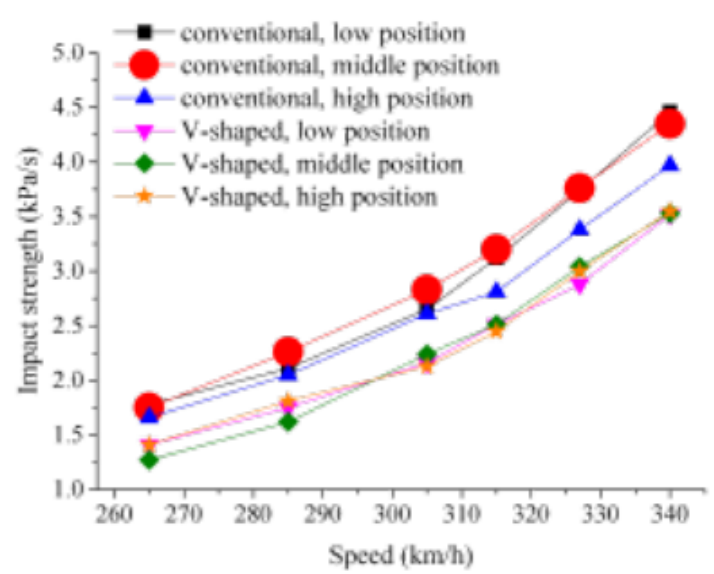

(a)

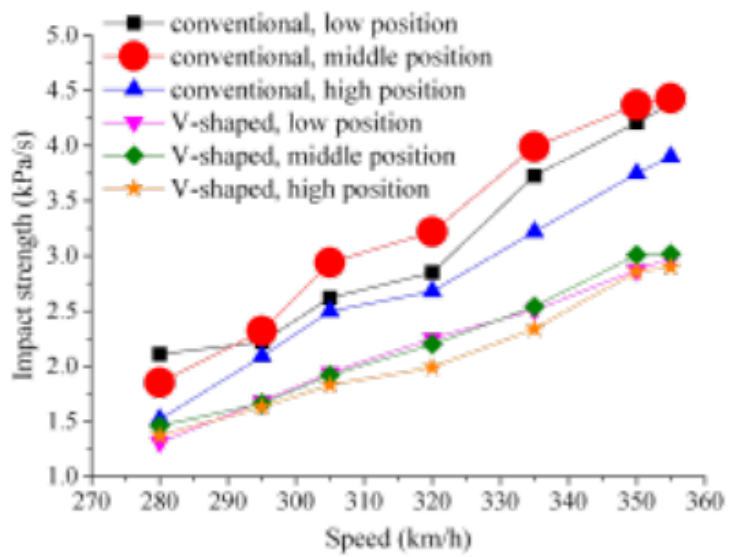

(b)

Figure 18. Average impact strength in vertical direction (a) CRH380AM passed the bridge section (b) CRH380A passed the east section on embankment.

Table 8. Average peak-trough deloading rate in vertical direction (\%).

\begin{tabular}{|c|c|c|c|}
\hline Case & $\begin{array}{c}\text { Low } \\
\text { position }\end{array}$ & $\begin{array}{c}\text { Middle } \\
\text { position }\end{array}$ & $\begin{array}{c}\text { High } \\
\text { position }\end{array}$ \\
\hline $\begin{array}{c}\text { CRH380AM passed } \\
\text { the bridge section } \\
\begin{array}{c}\text { CRH380A passed the east } \\
\text { section on embankment }\end{array}\end{array}$ & 17.76 & 18.79 & 15.36 \\
\hline
\end{tabular}

middle position where the air was squeezed more intensely on the surface of conventional noise barrier, the deloading rate increased correspondingly.

\section{CONCLUSIONS}

In this paper, a field test research was carried out to assess the aerodynamic deloading characteristics of a V-shaped noise barrier objectively. The impact strength and deloading rate of the peak and trough were investigated respectively, and the average impact strength as well as the average peak-trough deloading rate was calculated to compare the results of different measuring-sections quantitatively and figure out the effect of train shape on aerodynamic deloading characteristics. Meanwhile, the numerical simulation research was conducted to shed light on the deloading mechanism of the V-shaped noise barrier. The following conclusions can be drawn based on the research work mentioned above.

The air passage and the speed difference between the front and back of the V-shaped noise barrier promotes the escape of 


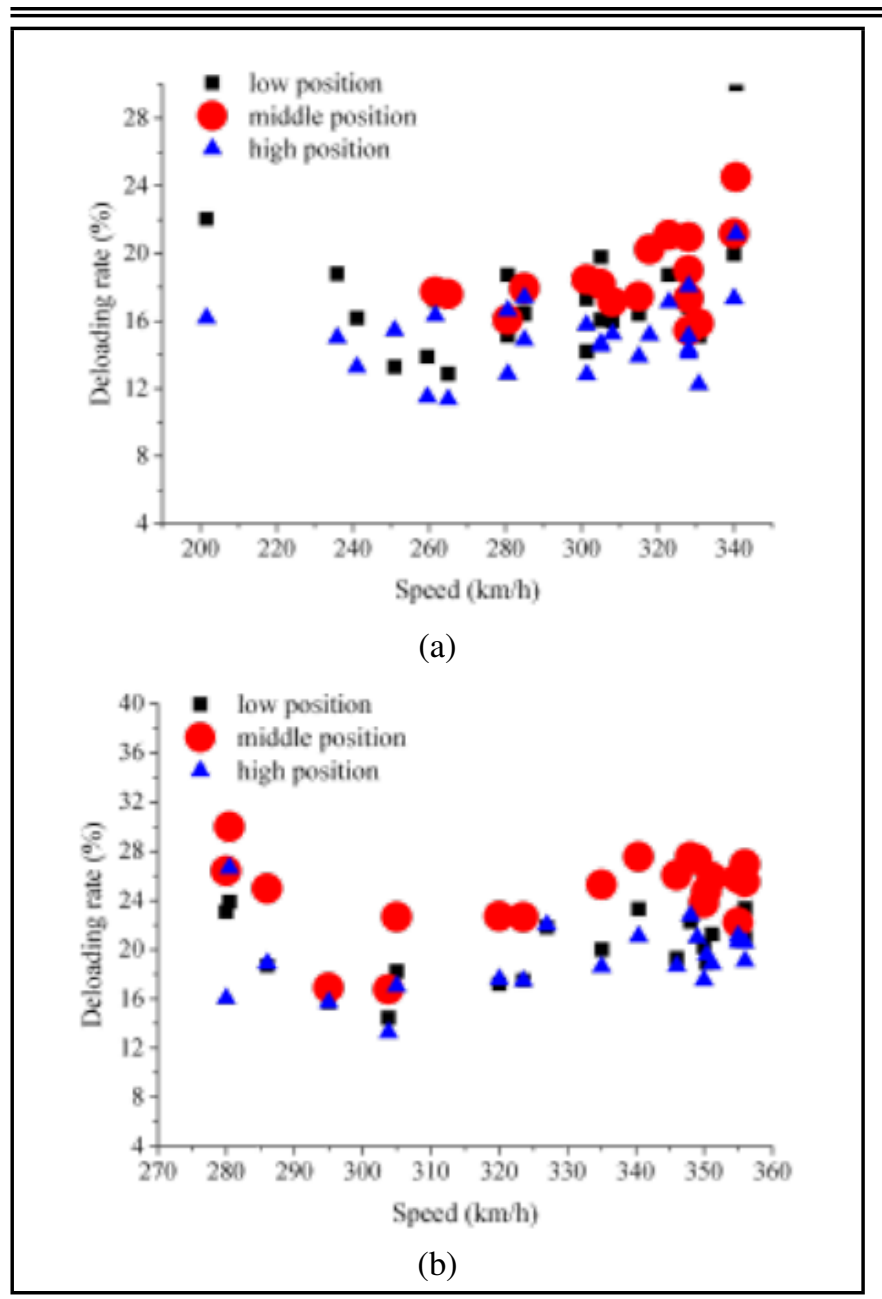

Figure 19. Vertical distribution of peak-trough deloading rate (a) CRH380AM passed the bridge section (b) CRH380A passed the east section on embankment.

the squeezed air into outer space, which results in lower pressure and weaker impact strength on the surface of the V-shaped noise barrier as opposed to the conventional one, and due to the much shorter action time, the trough impact strength is much stronger than the peak impact strength. The pressure gradient in the air passage prevents the pressure on the surface of the V-shaped noise barrier from declining further as oppose to the conventional one and promotes the external air to flow into the negative pressure zone generated by the headstock moving away gradually, which results in higher trough deloading rate as opposed to the peak deloading rate. What's more, the $\mathrm{V}$-shaped noise barrier is in favor of the uniform distribution of the aerodynamic load and balances the load-shedding effect during the whole process of pressure pulsing. In contrast with the CRH380A-type EMU, the CRH380AM-type EMU reduces the difference between the peak and trough deloading rate and improves the load-shedding effect for the weaker impact strength and slightly higher deloading rate induced by its passage.

\section{ACKNOWLEDGEMENT}

This project was supported by the National Natural Science Foundation of China (Grant No. 51776016, 51606006), Beijing Natural Science Foundation (Grant No. 3172025, 3182030), National Engineering Laboratory for Mobile Source Emission Control Technology (Grant No. NELMS2017A10), and the Talents Foundation of Beijing Jiaotong University (Grant No. 2018RC017).

\section{REFERENCES}

1 Coghlan, A. Hidden harm from noise pollution, New Scientist, 196 (2007) 25-25.

2 Naderzadeh, M., Monazzam, M.R., et al. Application of perforated sheets to improve the efficiency of reactive profiled noise barriers, Applied Acoustics, 72, 393-398, 2011. https://dx.doi.org/10.1016/j.apacoust.2011.01.002

3 Chen, X.D., et al. Numerical Simulation Study on highspeed train induced impulsive pressure on railway noise barrier based on ALE, Journal of the CHINA Railway Society, 33 (12), 22-26, 2011.

${ }^{4}$ Liu, W. Simulation research of aerodynamic load on sound barrier of high-speed railway, Master degree thesis, Beijing Jiaotong University, Beijing, 2014.

5 Liu, J.T. Aerodynamic load simulation and structural loading analysis of high-speed railway deloading noise barrier, Master degree thesis, Beijing Jiaotong University, Beijing, 2016.

${ }^{6} \mathrm{Li}, \mathrm{F}$. Study on characteristics of aerodynamic load on lessloading noise barrier based on laboratory experiments and simulation, Master degree thesis, Beijing Jiaotong University, Beijing, 2014.

7 Quinna, A.D., Baker, C.J., et al. Wind and vehicle induced forces on flat plates Part 1: wind induced force, Journal of Wind Engineering and Industrial Aerodynamics, 89, 817-829, 2001. https://dx.doi.org/10.1016/S01676105(01)00070-8

8 Quinna, A.D., Baker, C.J., et al. Wind and vehicle induced forces on flat plates Part 2: vehicle induced force, Journal of Wind Engineering and Industrial Aerodynamics, 89, 831-847, 2001. https://dx.doi.org/10.1016/S01676105(01)00071-X

9 Carassale, L., Brunenghi, M.M. Dynamic response of track side structures due to the aerodynamic effects produced by passing trains, Journal of Wind Engineering and Industrial Aerodynamics, 123, 317-324, 2013. https://dx.doi.org/10.1016/j.jweia.2013.09.005

10 Cali, P.M., Covert, E.E. Experimental measurements of the loads induced on an overhead highway sign structure by vehicle-induced gusts, Journal of Wind Engineering and Industrial Aerodynamics, 84, 87-100, 2000. https://dx.doi.org/10.1016/S0167-6105(99)00045-8

11 Lichtneger, P., Ruck, B. Full scale experiments on vehicle induced transient loads on roadside plates, Journal of Wind Engineering and Industrial Aerodynamics, 136, 7381, 2015. https://dx.doi.org/10.1016/j.jweia.2014.10.010

12 Shi, M. Experimental research of aerodynamic load on sound barrier of high-speed railway, Master degree thesis, Beijing Jiaotong University, Beijing, 2015. 